\title{
Derim sonrası UV-C ve etanol uygulamalarının Red Globe üzüm çeşidinin kalitesi ve muhafaza süresi üzerine etkileri
}

\section{Effects of postharvest UV-C and ethanol treatments on quality of cv. Red Globe grape and storage period}

\author{
Erdinç BAL ${ }^{1 *}$ (D) Ali i̇zzet TORÇUK ${ }^{2}$ (D) , Demir KÖK ${ }^{1}$ (D) \\ ${ }^{1}$ Tekirdağ Namık Kemal Üniversitesi, Ziraat Fakültesi, Bahçe Bitkileri Bölümü, Tekirdağ \\ ${ }^{2}$ Tekirdağ Bağcılık Araştırma Enstitüsü Müdürlüğü, Tekirdağ
}

To cite this article:

Bal, E., Torçuk, A.I. \& Kök, D. (2018). Derim sonrası UV-C ve etanol uygulamalarının Red Globe üzüm çeşidinin kalitesi ve muhafaza süresi üzerine etkileri. Harran Tarım ve Gıda Bilimleri Dergisi, 22(3): 335-347. DOI:

10.29050/harranziraat.3882 18

Address for Correspondence: Erdinç BAL

e-mail:

ebal@nku.edu.tr

Received Date:

02.02.2018

Accepted Date:

11.07.2018

(c) Copyright 2018 by Harran University Faculty of Agriculture. Available on-line at www.dergipark.gov.tr/harranziraat

\section{Öz}

Bu çalışma, 'Red Globe' üzüm çeşidinin soğukta muhafazası üzerine farklı dozlarda UV-C ışını uygulamaları ve etanol buhar pedlerinin tekli veya kombinasyonlarının, ticari olarak kullanılan kükürt dioksit $\left(\mathrm{SO}_{2}\right)$ jeneratörü ile karşılaştırılması amacıyla yürütülmüştür. Çalışmada, uygulamalar sonrasında salkımlar MAP torbalarda paketlenerek $0-1^{\circ} \mathrm{C}$ ve \%90-95 oransal nemli soğuk hava deposunda 3 ay süre ile muhafaza altına alınmıştır. Depolama sırasında aylık olarak, suda çözünebilir kuru madde içeriği, titre edilebilir asit miktarı, toplam fenolik madde miktarı, toplam antosiyanin miktarı ve antioksidan kapasite, salkım iskeleti rengi, çürüklük gelişimi ile dış görünüş gibi fiziksel ve kimyasal parametrelerde meydana gelen değişmeler incelenmiştir. Elde edilen sonuçlara göre, depolama süresi arttıkça üzüm kalitesinde kayıplar meydana gelmiştir. Uygulamalara bağlı olarak biyokimyasal bileşiklerde derim değerine göre muhafaza sonunda artış veya azalış şeklinde dalgalanmalar görülmüştür. Kontrol uygulamasında depolama süresi sonunda görülen çürüklük gelişimleri önemli düzeyde artmış ve pazarlanamaz seviyeye ulaşmıştır. Bunun yanında, 90 günlük depolama periyodu sonunda üzüm kalite özelliklerinin korunumu açısından en başarılı uygulama $\mathrm{SO}_{2}$ uygulaması olmuş ve bunu UV-C $1+$ Antimold 60 uygulaması izlemiştir.

Anahtar Kelimeler: Üzüm, Muhafaza, Etanol, UV-C, MAP

\section{ABSTRACT}

In this study, the effects of alone or combination treatments of different doses of UV-C irradiation and ethanol vapor pads on cold storage cv. Red Globe grape were compared with commercially available $\mathrm{SO}_{2}$ generator. Clusters were packaged in MAP bags and kept in $0-1{ }^{\circ} \mathrm{C}$ and $90-95 \%$ relative humidity cold air storage for 3 months after treatments. Monthly changes in physical and chemical parameters such as water soluble solids content, titratable acid content, total phenolic content, total anthocyanin content and antioxidant capacity, cluster skeleton color, decay development and appearance were investigated during storage. According to the results obtained, grape quality losses occurred along with increasing storage 
periods. Depending on the treatments, there are fluctuations in the biochemical compounds as the increase or decrease at the end of storage compared to the skin value. At the end of the storage period, the decay developments in control treatment increased significantly and reached to non-marketable levels. However, at the end of storage period, the most successful treatment for preserving of grape quality properties was the $\mathrm{SO}_{2}$ treatment, followed by UV-C $1+$ Antimold 60 treatment.

Key Words: Grape, Storage, Ethanol, UV-C, MAP

\section{Giriş}

Üzüm klimakterik olmayan, düşük fizyolojik aktiviteye sahip bir meyve türü olup, derim sonrası muhafazasını sınırlayan iki önemli faktör bulunmaktadır. Bunlardan ilki üzümlerden su kaybının meydana gelmesi ve ikincisi üzüm tanelerinin patojenlere karşı duyarlılık göstermeleridir (Türkben, 2010). Botrytis cinerea'nın neden olduğu kurşuni küf çürüklüğü üzümün muhafazasını sınırlayan önemli bir mantari hastalıktır. Bu hastalık derim sonrasında $\mathrm{SO}_{2}$ ile fümigasyon yapılarak kontrol edilmeye çalışılmaktadır (Söylemezoğlu, 2001). Günümüzde ticari olarak uygulanan yöntem; üzüm kasalarının özel olarak üretilmiş polietilen bazı belirli oranda gaz ve su buharı geçirgenliğine sahip Modifiye Atmosfer Poşeti (MAP) içerisine konulması ya da üzüm kasalarının içerisine $\mathrm{SO}_{2}$ uygulaması için sodyum metabisülfit pedleri ve bu kasalarında MAP içerisine konularak $0-1^{\circ} \mathrm{C}$ sıcaklık ve $\% 90 \pm 5$ oransal nem içeren soğuk hava deposuna yerleştirilerek muhafaza edilmesi şeklindedir.

$\mathrm{SO}_{2}$ uygulamaları bazı üzüm çeşitlerinde kaliteyi olumsuz yönde etkileyebilmektedir. Üzüm muhafazası esnasında aşırı miktardaki $\mathrm{SO}_{2}$ tanelerde ağarmaya, salkım iskeletinde kahverengileşmeye neden olmaktadır (Söylemezoğlu, 2001). Ayrıca tanede kalan $\mathrm{SO}_{2}$ kalıntılarının (>10 $\left.\mathrm{mg} / \mathrm{kg}\right)$ bazı tüketicilerde alerjik reaksiyonlara neden olduğu düşünülmektedir. Bu nedenle birçok ülkede $\mathrm{SO}_{2}$ uygulamalarına sınırlamalar getirilmiştir (Türk ve Doruk, 1992).

Yaş meyve ve sebzelerin muhafazası sırasında dayanımı artırmak ve çürümeleri önlemek amacıyla çeşitli çevre dostu uygulamaların kullanımı son yıllarda önem kazanmıştır.

Birçok gıda maddesinde doğal olarak bulunan etanol genelde emniyetli olarak kullanım statüsünde bir bileşik olarak kabul edilmekte olup, iyi imalat uygulamaları içerisinde kullanımına izin verilmektedir (Dentener ve ark., 1998). $\mathrm{SO}_{2}$ kullanımına alternatif olarak değişik üzüm çeşitlerinin muhafazasında MAP (Martinez-Romero ve ark. 2003; Artes-Hernandez ve ark., 2004) veya MAP+etanol (Litchter ve ark., 2002; Chervin ve ark., 2003; Lurie ve ark., 2006; Sabır ve ark., 2006; Sabır ve ark,. 2008) gibi uygulamalar kullanılmıştır.

Günümüzde derim sonrasında meyve ve sebzelerde, özellikle muhafaza ömürlerini uzatmak amacıyla, birçok farklı ışı uygulama yöntemleri de kullanılmaktadır. Bu yöntemlerden en yaygın olarak kullanılanları, iyonize radyasyon uygulamaları ve UV-C ışını uygulamalarıdır. Düşük dozlarda UV-C ışın uygulamaları ürüne zararlı etkilerde bulunmamaktadır. Bu nedenle bu tekniğin gıdalarda yüzeysel dezenfektan olarak kullanımına Amerika Birleşik Devletleri Gıda ve Illaç Birliği (Food Drug Agency, FDA) tarafından izin verilmiştir (Kasım ve Kasım 2007).

UV Işınları meyve ve sebzelerde 
çürümelere sebep olan mantarların gelişiminin engellenmesinde, kimyasal maddelerin nüfus edemeyeceği yerlere kadar girerek mikroorganizmalara ulaşabilmektedir. Aynı zamanda patojenlere karşı meyve kabuğunda direnç sağlayacak antimikrobiyal bileşiklerin birikimini de teşvik etmektedir (Stevens ve ark., 1996). Farklı çalışmalarda UV-C uygulamaları çürüklük etmenlerinin azaltılması ve kalitenin korunması amacıyla kullanılmıştır (Nigro ve ark., 1998; Akbudak ve Karabulut, 2002; Bal ve Kök, 2008; Keskin ve ark., 2015).

$\mathrm{Bu}$ araştırmada, $\mathrm{SO}_{2}$ uygulamasına alternatif olabilecek derim sonrası UV-C ışın uygulaması ve klasik etanol daldırma yönteminden farklı olarak etanol pedleri ile yapılan uygulamaların tekli veya kombinasyonları uygulanarak Red Globe üzüm çeşidinin soğukta muhafaza süresi uzatılmaya çalışılmıştır.

\section{Materyal ve Yöntem}

Araştırmada kullanılan Red Globe üzüm çeşidine ait salkımlar Tekirdağ ili Süleymanpaşa İlçesi'nin Mengen mevkiinde yer alan üretici bağından temin edilmiştir. 10.09.2016 tarihinde derimi yapılan salkımlarda ayıklama yapıldıktan sonra aşağıda belirtilen uygulamalar yapılmıştır.

\section{Kontrol}

MAP paketleri (FreshPlus) içine salkımlar yerleştirilerek paketlenmiştir.

\section{2. $\mathrm{SO}_{2}$ uygulaması}

MAP poşetleri içerisine bir adet $\mathrm{SO}_{2}$ jeneratörü $(\mathrm{g} / \mathrm{kg})$ yerleştirilmiştir.

\section{UV-C 1}

UV-C ışın uygulamasında her biri $2.5 \mathrm{~cm}$ çapında, $88 \mathrm{~cm}$ uzunluğunda 30 W çıkışlı, 254 $\mathrm{nm}$ dalga boyunda ışık yayan, 6 adet lamba (Philips-Holland) kullanılmıştır (Nigro ve ark., 1998). Uygulama kabininin $(60 \times 100 \times 100 \mathrm{~cm})$ alt ve üst kısmındaki lambalar ile 4 dakika süre ile $50 \mathrm{~cm}$ mesafeden uygulama yapılmıştır. Uygulama sonrası salkımlar MAP ile paketlenmiştir.

\section{UV-C 2}

UV-C ışın uygulamasında 8 dakika süre ile 50 cm mesafeden uygulama yapılmıştır. Uygulama sonrası salkımlar MAP ile paketlenmiştir.

\section{Antimold 60 uygulaması}

Her bir pakete içerisine 6 gram alkol içeren birer adet ped (Freund Co.Ltd., Tokyo, Japonya) konulmuş ve MAP ile paketlenmiştir.

\section{Antimold 80 uygulaması}

Her bir pakete içerisine 8 gram alkol içeren birer adet ped konulmuş ve MAP ile paketlenmiştir.

\section{UV-C $1+$ Antimold 60 uygulaması}

UV-C 1 uygulaması yapılmış olan salkımlar Antimold 60 pedleri ile birlikte MAP içerisinde paketlenmiştir.

\section{UV-C $1+$ Antimold 80 uygulaması}

UV-C 1 uygulaması yapılmış olan salkımlar Antimold 80 pedleri ile birlikte MAP içerisinde paketlenmiştir.

\section{UV-C $2+$ Antimold 60 uygulaması}

UV-C 2 uygulaması yapılmış olan salkımlar Antimold 60 pedleri ile birlikte MAP içerisinde paketlenmiştir.

\section{UV-C $2+$ Antimold 80 uygulaması}

UV-C 2 uygulaması yapılmış olan salkımlar Antimold 80 pedleri ile birlikte MAP içerisinde paketlenmiştir. 
Hazırlanan paketler $0-1^{\circ} \mathrm{C}$ ve $\% 90-95$ oransal neme sahip soğuk hava deposunda 3 ay süre ile muhafazaya alınmıştır. Depolama sırasında aylık olarak, suda çözünebilir kuru madde (SÇKM) miktarı (\%), titre edilebilir asit (TA) miktarı (\%), toplam fenolik madde miktarı (mg $100 \mathrm{~g}^{-1}$ ) (Slinkard ve Singleton, 1977), toplam antosiyanin miktarı (mg $100 \mathrm{~g}$ $\left.{ }^{1}\right)$ (Cemeroğlu, 2007), antioksidan kapasitesi

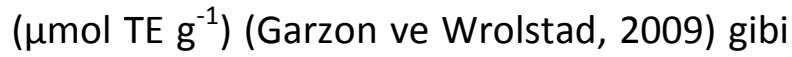
kimyasal; salkım iskeleti rengi (0: Parlak yeşil; 1: Yeşil; 2: Donuk mat yeşil; 3: Yeşil, hafif kahverengi; 4: Kahverengi; 5: Kurumuş grimsi kahverengi), çürüklük gelişimi (0: Sağlam, salkımlarda hiç hastalık belirtisi yok; 1: $A z$ hastalıklı, salkımlarda en fazla 5 tane lekeli veya çürük; 2 : Orta hastalıklı, salkımın 1/5'ne kadar lekeli veya çürük; 3: Çok hastalıklı, salkımın 2/5'ne kadar lekeli veya çürük; 4: Çok fazla hastalıklı, salkımın 3/5'ne kadar lekeli veya çürük) ile dış görünüş (13=pazarlanamaz, 5=pazarlanabilir, 7=iyi, $9=$ çok iyi) gibi fiziksel parametreler incelenmiştir.

Deneme tesadüf parselleri faktöriyel deneme desenine göre 3 tekerrürlü olarak kurulmuş ve her tekerrürde üçer adet paket (6 kg) yer almıştır. Elde edilen veriler "Minitab $15^{\prime \prime}$ istatistik paket programı yardımıyla varyans analizine tabi tutularak LSD çoklu karşılaştırma testiyle $\quad \mathrm{p}<0.05$ düzeyinde değerlendirilmiştir.

\section{Bulgular ve Tartışma}

\section{Suda Çözünür Kuru Madde Miktarı}

Araştırmada derim döneminde ortalama SÇKM \%15.90 iken, muhafaza süresi sonunda \%16.64 olarak tespit edilmiştir (Çizelge 1). SÇKM'deki değişim üzerine uygulamaların genel ortalaması incelendiğinde, en düşük ortalama SÇKM değeri $\mathrm{SO}_{2}$ uygulamasında (\%16.17), en yüksek ortalama SÇKM değeri ise Antimold 60 (\%16.54) uygulamasında görülmüştür. Denemede her iki faktörün interaksiyonu kapsamında genel olarak SÇKM değerlerinde artış saptanmıştır. En yüksek SÇKM değeri 3. ayda Antimold 60 uygulamasında (\%17.03), en düşük SÇKM değeri ise 1 . ay sonunda $\% 15.80 \quad \mathrm{SO}_{2}$ uygulamasında tespit edilmiştir.

Çizelge 1. 'Red Globe' üzüm çeşidinde derim sonrası farklı uygulamaların depolama süresince SçKM üzerine etkisi (\%)

Table 1. Influence of different postharvest treatments on SSC during storage period in 'Red Globe' grape cultivar (\%)

\begin{tabular}{|c|c|c|c|c|c|}
\hline & $\begin{array}{l}\text { Derim } \\
\text { Harvest }\end{array}$ & $\begin{array}{c}\text { 1. ay } \\
\text { First } \\
\text { month }\end{array}$ & $\begin{array}{c}\text { 2. ay } \\
\text { Second } \\
\text { month }\end{array}$ & $\begin{array}{l}\text { 3. ay } \\
\text { Third month }\end{array}$ & $\begin{array}{l}\text { Uygulama ortalaması } \\
\text { Treatment average }\end{array}$ \\
\hline Kontrol & $15.90 \mathrm{kl}$ & $16.13 j$ & $16.90 \mathrm{~b}$ & $16.90 \mathrm{~b}$ & $16.45 \mathrm{ABC}$ \\
\hline $\mathrm{SO}_{2}$ & $15.90 \mathrm{kl}$ & 15.801 & $16.53 \mathrm{ef}$ & $16.46 \mathrm{fg}$ & 16.17D \\
\hline UV-C 1 & $15.90 \mathrm{kl}$ & $16.43 \mathrm{fgh}$ & $16.13 j$ & $16.66 \mathrm{~cd}$ & $16.28 \mathrm{CD}$ \\
\hline UV-C 2 & $15.90 \mathrm{kl}$ & $15.96 \mathrm{k}$ & $16.93 a b$ & $16.66 \mathrm{~cd}$ & $16.36 \mathrm{ABC}$ \\
\hline Antimold 60 & $15.90 \mathrm{kl}$ & $16.33 \mathrm{~h}$ & $16.90 \mathrm{~b}$ & $17.03 a$ & $16.54 \mathrm{~A}$ \\
\hline Antimold 80 & $15.90 \mathrm{kl}$ & $16.63 \mathrm{de}$ & $16.36 \mathrm{gh}$ & $16.43 f g h$ & $16.33 \mathrm{BCD}$ \\
\hline UV-C $1+$ Antimold 60 & $15.90 \mathrm{kl}$ & $17.00 \mathrm{ab}$ & $16.76 c$ & $16.26 \mathrm{I}$ & $16.48 \mathrm{BCD}$ \\
\hline UV-C $1+$ Antimold 80 & $15.90 \mathrm{kl}$ & 16.96ab & $16.53 \mathrm{ef}$ & $16.63 \mathrm{de}$ & $16.50 \mathrm{AB}$ \\
\hline UV-C $2+$ Antimold 60 & $15.90 \mathrm{kl}$ & $15.90 \mathrm{kl}$ & $16.73 c d$ & $16.90 \mathrm{~b}$ & 16.35A-D \\
\hline UV-C $2+$ Antimold 80 & $15.90 \mathrm{kl}$ & $16.33 \mathrm{hı}$ & $16.66 \mathrm{~cd}$ & $16.43 \mathrm{fgh}$ & $16.33 \mathrm{BCD}$ \\
\hline $\begin{array}{l}\text { Zaman ortalaması } \\
\text { Time average }\end{array}$ & $15.90 \mathrm{C}$ & $16.35 \mathrm{~B}$ & $16.64 \mathrm{~A}$ & $16.64 \mathrm{~A}$ & \\
\hline
\end{tabular}


Araştırmada SÇKM değerlerindeki değişimlerin; üzüm salkımlarındaki tanelerin farklı olgunluklara sahip olmasından, uygulama farklılıklarından ve muhafaza süresinden kaynaklandığı düşünülebilir. Ancak, Cia ve ark. (2009)'nın yaptığı çalışmada ise, UV-C uygulaması yapılan üzümlerde meydana gelen SÇKM değişimlerinin çok fazla belirgin olmadığı tespit edilmiştir. Benzer şekilde Torçuk ve ark. (2016)’nın kirazlarda yaptığı çalışmada da etanol uygulamasının meyvelerin SÇKM içeriğini çok fazla değiştirmediği belirlenmiştir. Ağaoğlu ve ark. (1988) ile Tozlu (2001) ise Sultani Çekirdeksiz ve Müşküle üzüm çeşidinde soğukta muhafaza sırasında SÇKM içeriğinde artış ya da azalışlar olmuşsa da önemli bir değişim meydana gelmediğini bildirmişlerdir.

\section{Titre Edilebilir Asit Miktarı}

Üzüm TA miktarı düşük bir meyvedir ve depolama süresince azalışlar görülmektedir.
Araştırma sonuçlarına göre TA değerleri 3 aylık depolama periyodu sonunda başlangıç değerlerine göre önemli $(p<0.05)$ oranda azalmıştır. Derim döneminde üzümlerde ortalama TA değeri \%0.60 iken, 3. ayda ortalama \%0.51'e düşmüştür. Uygulamalar içerisinde en yüksek ortalama TA değeri $\% 0.58$ ile UV-C $2+$ Antimold 60 uygulamasında, en düşük ortalama TA değeri ise \%0.55 ile birbiriyle aynı ortalama değerleri alan Kontrol, UV-C 1, UV-C 2, Antimold 60 ve UV-C 1 + Antimold 80 uygulamalarında belirlenmiştir (Çizelge 2). Her iki faktörün interaksiyonu kapsamında genel olarak TA değerlerinde de düşüşler saptanmıştır. Depolama süresi sonunda üzümlerde tüm uygulamalarda TA miktarının kontrol grubuna göre daha yüksek çıktığı ve bu uygulamaların asit azalışını nispeten yavaşlattığı ortaya çıkmıştır. 90. günde en düşük ortalama TA miktarı Kontrol uygulamasında (\%0.48), en yüksek ortalama TA ise ile UV-C 2 + Antimold 60 (\%0.55) uygulamasında belirlenmiştir.

Çizelge 2. 'Red Globe' üzüm çeşidinde derim sonrası farklı uygulamaların depolama süresince TA miktarı üzerine etkisi (\%)

Table 2. Influence of different postharvest treatments on TA during storage period in 'Red Globe' grape cultivar (\%)

\begin{tabular}{|c|c|c|c|c|c|}
\hline & $\begin{array}{l}\text { Derim } \\
\text { Harvest }\end{array}$ & $\begin{array}{l}\text { 1. ay } \\
\text { First } \\
\text { month }\end{array}$ & $\begin{array}{l}\text { 2. ay } \\
\text { Second } \\
\text { month }\end{array}$ & $\begin{array}{l}\text { 3. ay } \\
\text { Third } \\
\text { month }\end{array}$ & $\begin{array}{c}\text { Uygulama } \\
\text { ortalaması } \\
\text { Treatment } \\
\text { average }\end{array}$ \\
\hline Kontrol & $0.60 \mathrm{abc}$ & $0.59 a-d$ & 0.52f-I & 0.481 & $0.55 \mathrm{D}$ \\
\hline $\mathrm{SO}_{2}$ & $0.60 a b c$ & $0.62 a b$ & ו-10.53e & ו-153e ו & $0.57 \mathrm{~B}$ \\
\hline UV-C 1 & $0.60 \mathrm{abc}$ & $0.57 b-f$ & $0.54 d-h$ & $0.50 \mathrm{gh}$ & $0.55 \mathrm{D}$ \\
\hline UV-C 2 & $0.60 a b c$ & $0.58 a-e$ & $0.50 \mathrm{gh}$ & ו-153e & $0.55 \mathrm{D}$ \\
\hline Antimold 60 & $0.60 \mathrm{abc}$ & $0.56 c-f$ & $0.55 c-g$ & 0.49hı & $0.55 \mathrm{D}$ \\
\hline Antimold 80 & $0.60 \mathrm{abc}$ & $0.60 a b c$ & $0.54 d-h$ & 0.49hı & $0.56 C$ \\
\hline UV-C $1+$ Antimold 60 & $0.60 a b c$ & $0.63 a$ & $0.54 d-h$ & ו ו-53e & $0.57 \mathrm{~B}$ \\
\hline UV-C $1+$ Antimold 80 & $0.60 \mathrm{abc}$ & $0.60 \mathrm{abc}$ & 0.52f-I & ו-0.49h & $0.55 \mathrm{D}$ \\
\hline UV-C $2+$ Antimold 60 & $0.60 a b c$ & $0.60 a b c$ & $0.58 a-e$ & $0.55 \mathrm{c}-\mathrm{g}$ & $0.58 \mathrm{~A}$ \\
\hline UV-C $2+$ Antimold 80 & $0.60 \mathrm{abc}$ & $0.59 a-d$ & $0.55 c-g$ & $0.50 \mathrm{gh}$ & $0.56 \mathrm{C}$ \\
\hline $\begin{array}{l}\text { Zaman ortalaması } \\
\text { Time average }\end{array}$ & $0.60 \mathrm{~A}$ & $0.60 \mathrm{~A}$ & $0.54 \mathrm{~B}$ & $0.51 C$ & \\
\hline LSD uygulama x zaman: 5.13 & & & & & \\
\hline
\end{tabular}

Çalışmada uygulamalar arasındaki süresinin ilerlemesiyle üzümlerin TA farklılıklar önemli çıkmış olsa da, depolama miktarında görülen değişimler sınırlı 
olmuştur. Elde edilen verilere benzer olarak, farklı çalışmalarda da üzümlerde TA içeriğinin muhafazanın sonuna doğru azaldığı ve bu azalmanın çeşitlere ve uygulamalara göre değişmekle birlikte sınırlı miktarda olabildiği bildirilmiştir (Artes-Hernandez ve ark., 2004; Bal ve Kök, 2008; Şen ve Kesgin, 2014).

\section{Toplam Fenolik Bileşik Miktarı}

Fenolik bileşikler üzümün özellikle renk, tat ve aroma özelliklerinde büyük rol oynamakta olup üzümlerin fenol miktarı derim olgunluğuna, derim yöntemlerine, iklim ve depolama sıcaklıklarına göre değişebilmektedir (Kök ve ark., 2017). Araştırmada bu özellikler yönünden uygulamalara bağlı olarak değişimler görülmüş ve derim değerine göre muhafaza sonunda artış veya azalış saptanmıştır (Çizelge 3). Denemede depolama süresince uygulamalar içerisinde en yüksek toplam fenolik bileşik miktarı 2. ayda UV-C 2 uygulamasında (307.0 mg $100 \mathrm{~g}^{-1}$ ) görülürken, en düşük toplam fenolik bileşik miktarı ise 3 . ayda UV-C 2 + Antimold 60 uygulamasında (172.7 $\left.\mathrm{mg} 100 \mathrm{~g}^{-1}\right)$ tespit edilmiştir. 1. ayda tüm uygulamalarda fenolik bileşik içeriği bakımında artış tespit edilmiştir. Bu artışın sebebi uygulamaların etkisinden kaynaklanabileceği gibi soğuk stresi nedeniylede ortaya çıkabileceği düşünülmektedir. Genel olarak UV-C uygulaması yapılan salkımlarda fenolik bileşik miktarı nispeten daha yüksek bulunmuştur. $\mathrm{Bu}$ artışında ultraviyole ışınların meyve bünyesinde bulunan biyoaktif bileşiklerin değişimine etkisinden kaynaklandığı düşünülmektedir. Marquenie ve ark. (2002) ile Rivera ve ark. (2007), UV-C uygulamalarının meyveler üzerindeki etkinliğinin meyve yüzeyinde mikroorganizmaları öldürerek veya fenolik maddeler, fitoaleksinler, poliaminler gibi savunma mekanizması ile ilgili olan bileşiklerin sentezini artırarak gerçekleştiğini belirtmiştir. Erkan ve ark. (2008)'da farklı UVC dozları ile uyarılmış çileğin toplam fenolik bileşik miktarının kontrole göre önemli oranda arttığını bildirmiştir. Antimold uygulamalarının üzümlerin fenolik madde içeriği üzerine önemli bir etki gösteremediği görülmüştür.

Çizelge 3. 'Red Globe' üzüm çeşidinde derim sonrası farklı uygulamaların depolama süresince toplam fenolik bileşikler üzerine etkisi $\left(\mathrm{mg} 100 \mathrm{~g}^{-1}\right)$

Table 3. Influence of different postharvest treatments on total phenolic content during storage period in 'Red

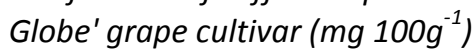

\begin{tabular}{|c|c|c|c|c|c|}
\hline & $\begin{array}{l}\text { Derim } \\
\text { Harvest }\end{array}$ & $\begin{array}{l}\text { 1. ay } \\
\text { First } \\
\text { month }\end{array}$ & $\begin{array}{c}\text { 2. ay } \\
\text { Second month }\end{array}$ & $\begin{array}{l}\text { 3. ay } \\
\text { Third month }\end{array}$ & $\begin{array}{c}\text { Uygulama } \\
\text { ortalaması } \\
\text { Treatment } \\
\text { average }\end{array}$ \\
\hline Kontrol & 198.7f-I & 206.9e-I & 197.1ghı & $222.4 c-h$ & 206.3CD \\
\hline $\mathrm{SO}_{2}$ & 198.7f-ו & $221.7 c-h$ & $251.7 b-e$ & $230.5 c-h$ & $225.6 \mathrm{BC}$ \\
\hline UV-C 1 & 198.7f-ו & $258.0 \mathrm{bcd}$ & $245.3 b-f$ & $267.2 \mathrm{abc}$ & $242.3 B$ \\
\hline UV-C 2 & 198.7f-ו & $281.6 a b$ & 307.0a & $287.5 \mathrm{ab}$ & $268.7 A$ \\
\hline Antimold 60 & 198.7f-ו & $233.0 \mathrm{c}-\mathrm{g}$ & 219.8c-I & $183.1 \mathrm{ch}$ & 208.6CD \\
\hline Antimold 80 & 198.7f-ו & $231.7 c-g$ & $229.6 c-h$ & 214.5d-I & 218.6BCD \\
\hline UV-C $1+$ Antimold 60 & 198.7f-ו & 209.1e-I & 188.1ghı & 200.2f-I & 199.0D \\
\hline UV-C $1+$ Antimold 80 & ו-198.7f ו & 201.6f- ا & 213.1d-I & 190.0ghı & $200.8 C D$ \\
\hline UV-C $2+$ Antimold 60 & 198.7f-ו & $228.5 c-h$ & 193.3ghı & 172.7ו & 198.3D \\
\hline UV-C $2+$ Antimold 80 & 198.7f-ו & $222.8 c-h$ & 207.2e-I & $228.8 c-h$ & $214.4 C D$ \\
\hline $\begin{array}{l}\text { Zaman ortalaması } \\
\text { Time average }\end{array}$ & 198.7B & $229.5 A$ & $225.2 A$ & 219.7A & \\
\hline
\end{tabular}


Toplam antosiyanin miktarı

Antosiyaninler, yaygın olarak üzümlerin kabuğundaki hipodermisin ilk 3-4 hücre tabakasında bulunmaktadırlar (Winkler ve ark., 1974). Araştırmada Red Globe üzüm çeşidinde toplam antosiyanin miktarında dalgalanmalar ile birlikte genel olarak başlangıca göre artış görülmüştür. Derim döneminde ortalama toplam antosiyanin

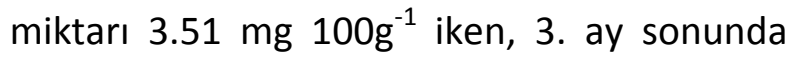
$4.77 \mathrm{mg} 100 \mathrm{~g}^{-1_{1}}$ a yükselmiştir (Çizelge 4). Yapılan farklı çalışmalarda da soğukta depolanan üzümlerin çeşidine bağlı olarak toplam antosiyanin içeriğinde artış veya azalışlar tespit edilmiştir (Artes-Hernandez ve ark., 2004; Romero ve ark., 2008; Bal ve ark., 2011). Muhafaza süresince en yüksek toplam antosiyanin miktarı 3. ayda UV-C 2 uygulamasında $\left(6.55 \mathrm{mg} 100 \mathrm{~g}^{-1}\right)$ görülmüş ve bunu $\mathrm{SO}_{2}$ uygulaması (6.24 mg $100 \mathrm{~g}^{-1}$ ) izlemiştir, en düşük toplam antosiyanin miktarı ise 1.ayda UV-C 1 uygulamasında (2.54 mg $100 \mathrm{~g}^{-1}$ ) belirlenmiştir. 3. ay sonunda en düşük toplam antosiyanin miktarı ise Kontrol grubunda (3.25 mg $100 \mathrm{~g}^{-1}$ ) tespit edilmiştir. Üzümlerdeki bu değişimin biyokimyasal yapılarındaki değişkenlikler veya salkım üzerinde yer alan taneler arasında da renklenmede farklılıklara rastlanmasından kaynaklandığı düşünülmektedir. UV-C 2 dozunun antosiyanin içeriğini olumlu olarak etkilediği görülmüştür. Çalışmada elde edilen bulgular, araştırmacıların elma, çilek ve kiraz meyvelerinde (Dong ve ark., 1995; Erkan ve ark., 2008; Koçak ve Bal, 2017) UV-C uygulamasının bu parametre üzerindeki etkileriyle uyum göstermektedir.

Çizelge 4. 'Red Globe' üzüm çeşidinde derim sonrası farklı uygulamaların depolama süresince toplam antosiyanin üzerine etkisi

Table 4. Influence of different postharvest treatments on total anthocyanin content during storage period in 'Red Globe' grape cultivar $\left(\mathrm{mg} 100 \mathrm{~g}^{-1}\right)$

\begin{tabular}{|c|c|c|c|c|c|}
\hline & $\begin{array}{l}\text { Derim } \\
\text { Harvest }\end{array}$ & $\begin{array}{l}\text { 1. ay } \\
\text { First } \\
\text { month }\end{array}$ & $\begin{array}{c}\text { 2. ay } \\
\text { Second month }\end{array}$ & $\begin{array}{l}\text { 3. ay } \\
\text { Third } \\
\text { month }\end{array}$ & $\begin{array}{c}\text { Uygulama } \\
\text { ortalaması } \\
\text { Treatment } \\
\text { average }\end{array}$ \\
\hline Kontrol & $3.51 \mathrm{c}-\mathrm{g}$ & $2.92 \mathrm{efg}$ & $4.09 b-g$ & $3.25 \mathrm{~d}-\mathrm{g}$ & 3.44 \\
\hline $\mathrm{SO}_{2}$ & $3.51 \mathrm{c}-\mathrm{g}$ & $3.92 \mathrm{c}-\mathrm{g}$ & $3.32 \mathrm{~d}-\mathrm{g}$ & $6.24 a b$ & 4.25 \\
\hline UV-C 1 & $3.51 \mathrm{c}-\mathrm{g}$ & $2.54 \mathrm{~g}$ & $3.52 \mathrm{c}-\mathrm{g}$ & $4.13 b-g$ & 3.42 \\
\hline UV-C 2 & $3.51 \mathrm{c}-\mathrm{g}$ & $3.94 \mathrm{c}-\mathrm{g}$ & 4.67a-g & $6.55 a$ & 4.67 \\
\hline Antimold 60 & $3.51 \mathrm{c}-\mathrm{g}$ & $3.95 c-g$ & 6.19ab & 5.06a-e & 4.68 \\
\hline Antimold 80 & $3.51 c-g$ & $2.98 \mathrm{efg}$ & 4.98a-f & $5.65 a b c$ & 4.28 \\
\hline UV-C $1+$ Antimold 60 & $3.51 \mathrm{c}-\mathrm{g}$ & $2.77 f g$ & $4.58 a-g$ & $4.26 b-g$ & 3.78 \\
\hline UV-C $1+$ Antimold 80 & $3.51 \mathrm{c}-\mathrm{g}$ & $3.51 \mathrm{c}-\mathrm{g}$ & $3.57 \mathrm{c}-\mathrm{g}$ & $4.14 \mathrm{~b}-\mathrm{g}$ & 3.68 \\
\hline UV-C $2+$ Antimold 60 & $3.51 c-g$ & $3.69 c-g$ & $5.31 a-d$ & 4.71a-g & 4.31 \\
\hline UV-C $2+$ Antimold 80 & $3.51 \mathrm{c}-\mathrm{g}$ & 5.40a-d & $3.45 c-g$ & $3.70 \mathrm{cg}$ & 4.01 \\
\hline $\begin{array}{l}\text { Zaman ortalaması } \\
\text { Time average }\end{array}$ & $3.51 B$ & $3.56 \mathrm{~B}$ & $4.37 \mathrm{~A}$ & 4.77A & \\
\hline
\end{tabular}

\section{Antioksidan kapasitesi}

Meyve ve sebzelerin soğukta depolama süresince içerdikleri biyokimyasal bileşiklerin seviyelerini etkileyen faktörlerin başında çeşidin özellikleri, olgunluk seviyesi ve depolama koşulları gelmektedir. Yapılan bu araştırmada, kontrol ve Antimold 60 uygulamasında antioksidan kapasitesi depolamanın ilk döneminde düşerken, diğer uygulamalarda artış gerçekleşmiştir (Çizelge 
5). 3. ayda ise en yüksek antioksidan miktarı $\mathrm{SO}_{2}$ uygulamasında $\left(3.02 \mu \mathrm{mol}\right.$ TE $\left.\mathrm{g}^{-1}\right)$ görülmüş ve bunu UV-C 2 uygulaması (2.81 $\mu \mathrm{mol}$ TE $\mathrm{g}^{-1}$ ) izlemiştir, en düşük toplam antioksidan miktarı ise Kontrol uygulamasında $\left(1.84 \quad \mu \mathrm{mol} \quad \mathrm{TE} \quad \mathrm{g}^{-1}\right)$ belirlenmiştir. Araştırmada depolama süresine ilişkin değerler incelendiğinde, derim döneminde ortalama antioksidan kapasitesi $2.60 \mu \mathrm{mol} \mathrm{TE} \mathrm{g}^{-1}$ iken, 1. ayda $2.93 \mu \mathrm{mol} \mathrm{TE} \mathrm{g}$ ${ }^{1} \mathrm{e}$ yükselmiş, muhafaza süresi sonunda ise

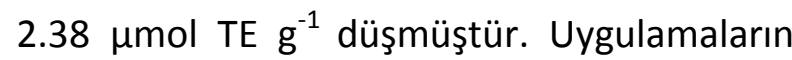
genel ortalaması incelendiğinde, en düşük ortalama antioksidan kapasitesi değeri Antimold 60 uygulamasında $(2.43 \mu \mathrm{mol}$ TE g${ }^{1}$ ), en yüksek ortalama antioksidan kapasitesi değeri ise UV-C 2 (3.10 $\mu \mathrm{mol}$ TE $\left.\mathrm{g}^{-1}\right)$ uygulamasında görülmüştür.
Genel olarak UV-C'nin tekli ve kombinasyon uygulandığı üzümlerde ilk ayda artışlar meydana gelmiş ve sonrasında deneme sonuna kadar dalgalanmalar tespit edilmiştir. UV-C uygulamasının benzer etkileri; Vicente ve ark. (2005), Costa ve ark. (2006), Erkan ve ark. (2008) ve Koçak ve Bal (2017) yaptıkları çalışmalarda farklı meyve ve sebzelerde antioksidan madde birikimini artırdığını bildirmişlerdir. 3 aylık depolama süresi sonunda $\mathrm{SO}_{2}$ ve UV-C 2 uygulanmış üzümlerde antioksidan kapasitesi en yüksek seviyede bulunmuştur. Bu çalışmanın sonuçlarına benzer şekilde, Valizadeh (2015) üzümlerde antioksidan aktivitesini $\mathrm{SO}_{2}$ uygulamasının muhafaza süresince önemli seviyede koruduğunu tespit etmişdir.

Çizelge 5. 'Red Globe' üzüm çeşidinde derim sonrası farklı uygulamaların depolama süresince antioksidan kapasite üzerine etkisi ( $\mu \mathrm{mol} \mathrm{TE} \mathrm{\textrm {g } ^ { - 1 } )}$

Table 5. Influence of different postharvest treatments on antioxidant capacity during storage period in 'Red Globe' grape cultivar $\left(\mu \mathrm{mol} T \mathrm{TE}^{-1}\right)$

\begin{tabular}{|c|c|c|c|c|c|}
\hline & $\begin{array}{l}\text { Derim } \\
\text { Harvest }\end{array}$ & $\begin{array}{l}\text { 1. ay } \\
\text { First } \\
\text { month }\end{array}$ & $\begin{array}{l}\text { 2. ay } \\
\text { Second } \\
\text { month }\end{array}$ & $\begin{array}{l}\text { 3. ay } \\
\text { Third } \\
\text { month }\end{array}$ & $\begin{array}{c}\text { Uygulama } \\
\text { ortalaması } \\
\text { Treatment } \\
\text { average }\end{array}$ \\
\hline Kontrol & $2.60 c-j$ & $2.48 \mathrm{e}-\mathrm{j}$ & $2.90 \mathrm{~b}-\mathrm{g}$ & $1.84 \mathrm{j}$ & $2.45 C D$ \\
\hline $\mathrm{SO}_{2}$ & $2.60 c-j$ & $2.79 b-1$ & $3.17 \mathrm{bcd}$ & $3.02 \mathrm{~b}-\mathrm{e}$ & $2.89 \mathrm{AB}$ \\
\hline UV-C 1 & $2.60 c-j$ & $2.70 c-1$ & $2.22 \mathrm{~g}-\mathrm{j}$ & $2.55 c-j$ & $2.52 C D$ \\
\hline UV-C 2 & $2.60 c-j$ & $4.24 a$ & $2.76 c-1$ & 2.81b-I & $3.10 \mathrm{~A}$ \\
\hline Antimold 60 & $2.60 c-j$ & $2.46 e-j$ & $2.51 d-j$ & 2.13hij & $2.43 \mathrm{D}$ \\
\hline Antimold 80 & $2.60 c-j$ & $2.74 c-1$ & $3.47 \mathrm{~b}$ & $2.36 e-j$ & 2.79ABC \\
\hline UV-C $1+$ Antimold 60 & $2.60 c-j$ & $2.93 b-f$ & $2.73 c-1$ & $2.01 j$ & $2.56 \mathrm{BCD}$ \\
\hline UV-C $1+$ Antimold 80 & $2.60 c-j$ & $2.84 \mathrm{~b}-\mathrm{g}$ & $2.77 c-1$ & $2.11 i j$ & $2.58 \mathrm{BCD}$ \\
\hline UV-C $2+$ Antimold 60 & $2.60 c-j$ & $2.93 b-f$ & 2.15hij & $2.30 f-j$ & $2.50 \mathrm{CD}$ \\
\hline UV-C $2+$ Antimold 80 & $2.60 c-j$ & $3.22 \mathrm{bc}$ & $2.31 \mathrm{f}-\mathrm{j}$ & $2.72 \mathrm{c}-1$ & 2.71BCD \\
\hline $\begin{array}{l}\text { Zaman ortalaması } \\
\text { Time average }\end{array}$ & $2.60 \mathrm{BC}$ & $2.93 \mathrm{~A}$ & $2.70 \mathrm{~B}$ & $2.38 \mathrm{C}$ & \\
\hline
\end{tabular}

LSD uygulama x zaman: $0.68 \quad L_{\text {uygulama }}: 0.349 \quad$ LSD $_{\text {zaman }}: 0.21$

\section{Salkım iskeleti rengi}

Depolama boyunca üzüm salkım iskeleti esmerleşmesi değerlerinin soğukta muhafaza sonunda başlangıç verilerine göre arttığı tespit edilmiştir. Uygulamalar içerisinde en az salkım iskeleti kararması $\mathrm{SO}_{2}$ uygulamasında
(1.41), en fazla salkım iskeleti kararması ise Antimold 80 (2.22) uygulanmış salkımlarda belirlenmiştir (Çizelge 6). Salkımlar muhafaza süresine paralel bir şekilde artan bir kararma göstermişlerdir. Muhafaza süresi sonunda ise en az kararma 2.96 puan ile $\mathrm{SO}_{2}$ 
uygulamasında görülürken bunu UV-C $1+$ Antimold 60 (3.33) ve UV-C $2+$ Antimold 60 (3.46) izlemiştir. En yüksek kararma ise 4.06 puan ile Antimold 80 uygulanmış salkımlarda tespit edilmiştir.

Araştırmada sofralık üzümde pazarlanabilirliği çok önemli düzeyde etkileyen salkım iskeleti rengini depolama süresince $\mathrm{SO}_{2}$ uygulaması en yüksek oranda korumuştur. $\mathrm{SO}_{2}$ 'nin kararmalarda rol oynayan polifenol oksidaz enzim aktivitesini azaltarak, derimdeki tane sapı ve salkım iskeleti rengini koruduğu bildirilmiştir (Deng ve ark., 2005). Benzer şekilde farklı üzüm çeşitlerinde yapılan çalışmalarda da kükürt uygulamasının salkım iskeleti rengini korumada uçucu bileşik ve etanol uygulamasından daha etkili olduğu belirtilmektedir (Özkaya ve ark. 2005; Bal ve Kök 2008; Bal ve ark. 2011; Erbaş ve ark. 2014). Sonuçlar literatür çalışmalarıyla paralellik göstermektedir. UV-C Işın uygulamalarının etkinliğinin Antimold 60 uygulamasıyla birlikte arttığı görülmüştür. UV-C 1 + Antimold 60 ve UV-C 2 + Antimold 60 uygulamaları $\mathrm{SO}_{2}$ uygulamasından sonra salkımlarda en az kararmaların görüldüğü uygulamalar olmuştur. Çandır ve ark. (2010)'da 'Red Globe' üzüm çeşidini MAP, $\mathrm{MAP}+$ etanol generatörü, $\mathrm{MAP}+\mathrm{SO}_{2}$ ve delikli polietilen poşet $+\mathrm{SO}_{2}$ kullanarak $0^{\circ} \mathrm{C}^{\prime}$ de muhafaza etmiş, muhafaza sonunda meyvedeki sap esmerleşmelerinin önlenmesinde $\mathrm{SO}_{2}$ ile kombineli $\mathrm{MAP}$ ve delikli polietilen uygulamalarının, sadece MAP ve etanol generatörü + MAP uygulamalarına göre daha etkili olduğunu bildirmiştir. Antimold 80 uygulanmış bazı salkımlarda ise kararmaların daha fazla oluşmasının MAP içerisinde etanolün yüksek seviyede bulunmasından kaynaklanabileceği düşünülmektedir. Benzer şekilde Chervin ve ark. (2005) ile Lurie ve ark. (2006)'da üzümlerde yapılan çalışmada belirli dozun üzerindeki etanol buharının kararmalara yol açtığını bildirmiştir.

Çizelge 6. 'Red Globe' üzüm çeşidinde derim sonrası farklı uygulamaların depolama süresince salkım iskeleti rengi üzerine etkisi (0-5 puan)

Table 6. Influence of different postharvest treatments on cluster skeleton color during storage period in 'Red Globe' grape cultivar (0-5 point)

\begin{tabular}{|c|c|c|c|c|c|}
\hline & $\begin{array}{l}\text { Derim } \\
\text { Harvest }\end{array}$ & $\begin{array}{c}\text { 1. ay } \\
\text { First } \\
\text { month }\end{array}$ & $\begin{array}{l}\text { 2. ay } \\
\text { Second } \\
\text { month }\end{array}$ & $\begin{array}{l}\text { 3. ay } \\
\text { Third month }\end{array}$ & $\begin{array}{c}\text { Uygulama } \\
\text { ortalaması } \\
\text { Treatment } \\
\text { average }\end{array}$ \\
\hline Kontrol & Oa & $1.26 \mathrm{cde}$ & $2.90 \mathrm{~g}-\mathrm{j}$ & $3.86 o p$ & $2.01 C D$ \\
\hline $\mathrm{SO}_{2}$ & Oa & $0.50 \mathrm{~b}$ & $2.16 f$ & $2.96 ı j k$ & $1.41 \mathrm{~A}$ \\
\hline UV-C 1 & Oa & $1.46 \mathrm{~lm}$ & $2.86 \mathrm{~g}-\mathrm{j}$ & $3.63 \mathrm{mno}$ & $1.99 \mathrm{CD}$ \\
\hline UV-C 2 & Oa & $1.56 \mathrm{e}$ & 3.10jkl & 3.93op & 2.15DE \\
\hline Antimold 60 & Oa & $1.40 \mathrm{cde}$ & 2.60ghı & $3.66 \mathrm{mno}$ & $1.91 B C$ \\
\hline Antimold 80 & Oa & $1.63 e$ & $3.20 \mathrm{jkl}$ & $4.06 p$ & $2.22 \mathrm{E}$ \\
\hline UV-C 1 + Antimold 60 & Oa & $1.40 \mathrm{cde}$ & 2.93hıj & $3.33 \mathrm{klm}$ & $1.86 \mathrm{BC}$ \\
\hline UV-C $1+$ Antimold 80 & Oa & $1.06 c$ & $2.53 \mathrm{fg}$ & 3.83nop & $1.86 \mathrm{BC}$ \\
\hline UV-C $2+$ Antimold 60 & Oa & $1.13 \mathrm{~cd}$ & $2.56 \mathrm{gh}$ & $3.461 \mathrm{mn}$ & $1.79 B$ \\
\hline UV-C $2+$ Antimold 80 & $0 \mathrm{a}$ & $1.50 \mathrm{de}$ & $2.66 \mathrm{gh}$ । & 3.90op & 2.01CD \\
\hline $\begin{array}{l}\text { Zaman ortalaması } \\
\text { Time average }\end{array}$ & OA & $1.29 B$ & $2.75 \mathrm{C}$ & $3.66 \mathrm{D}$ & \\
\hline LSD uygulama x zaman: 0.37 & $: 0.18$ & $\mathrm{LSD}_{\text {zama }}$ & & & \\
\hline
\end{tabular}


Çürüklük gelişimi

Muhafaza periyodu boyunca meydana gelen fizyolojik ve mantarsal nedenli bozukluklar saptanarak 0-4 skalasına göre hesaplanmıştır. Denemede uygulamalar içerisinde en az çürüklük gelişimi $\mathrm{SO}_{2}$ uygulamasında (0.22 puan), en fazla çürüklük gelişimi ise Kontrol grubundaki (1.33 puan) salkımlarda belirlenmiştir (Çizelge 7). Depolama boyunca üzüm salkımlarındaki patojen ve fizyolojik kaynaklı kayıplar soğukta muhafaza süresi sonunda başlangıç verilerine göre artış göstermiştir. 1. ayda tüm salkımlarda çürümeye rastlanmazken, 2. ayda $\mathrm{SO}_{2}$ hariç bütün uygulamalarda değişen oranlarda çürüklüklere rastlanmaya başlanmıştır. 3. ayda yapılan incelemelerde ise en düşük çürüklük gelişimi $\mathrm{SO}_{2}$ uygulaması (0.66 puan) başta olmak üzere UV-C $1+$ Antimold 60 (1 puan) ve UV-C $2+$ Antimold 60 (1.11 puan) uygulamalarınınsalkımlarda çürüklük kontrolünde etkili olduğu belirlenmiştir. Muhafaza süresi sonunda en yüksek çürüklük gelişimi puanı ise Kontrol grubunda (3.14 puan) belirlenmiştir. Daha önce yürütülen bazı çalışmaların (Nigro ve ark., 1998; Akbudak ve Karabulut, 2002; Chervin ve ark., 2005; Lurie ve ark., 2006; Sabır ve ark., 2008) sonuçlarına benzer şekilde, bu çalışmada elde edilen bulgularda da, etanol ve UV-C uygulamaları çürümelerin azaltılmasında farklı seviyelerde kontrole göre daha olumlu etkide bulunmuştur. Ancak $\mathrm{SO}_{2}$ uygulaması diğer uygulamalara göre Botrytis cinerea mantarının neden olduğu çürüklük gelişiminin sınırlandırılmasında en etkili uygulama olmuştur. $\mathrm{SO}_{2}$ uygulamasından sonra en etkili uygulama ise UV-C $1+$ Antimold 60 uygulaması olmuştur. Tekli uygulamalara göre kombinasyon uygulamalarının çürüklük gelişimini sınırlandırmada daha etkili olduğu belirlenmiştir. Antimold ve UV-C tekli uygulamalarının 2. ayda da etkili olduğu, ancak 3. ayda etkinliklerini yitirdiği düşünülmektedir. Benzer şekilde Sabır ve ark. (2006) ile Çandır ve ark. (2010)'nın farklı üzüm çeşitlerinin soğukta muhafazası üzerine $\mathrm{SO}_{2}$ jeneratörü ve farklı dozlardaki etanol uygulamalarının etkilerini karşılaştırdıkları çalışmalarda, etanol uygulamalarının $\mathrm{SO}_{2}$ uygulamasına alternatif olabileceği, ancak uzun süreli depolamada tanelerde Botrytis cinerea zararı ve salkım sapı kararmalarına karşı yeterli koruma sağlamayabileceği sonucuna varılmıştır.

Çizelge 7. 'Red Globe' üzüm çeşidinde derim sonrası farklı uygulamaların depolama süresince çürüklük gelişimi üzerine etkisi (0-4 puan)

Table 7. Influence of different postharvest treatments on decay development during storage period in 'Red Globe' grape cultivar (0-5 point)

\begin{tabular}{lcccc}
\hline & $\begin{array}{c}\text { 1. ay } \\
\text { First month }\end{array}$ & $\begin{array}{c}\text { 2. ay } \\
\text { Second month }\end{array}$ & $\begin{array}{c}\text { 3. ay } \\
\text { Third month }\end{array}$ & $\begin{array}{c}\text { Uygulama ortalaması } \\
\text { Treatment average }\end{array}$ \\
\hline Kontrol & $0 \mathrm{a}$ & $0.85 \mathrm{cde}$ & $3.14 \mathrm{l}$ & $1.33 \mathrm{~F}$ \\
$\mathrm{SO}_{2}$ & $0 \mathrm{a}$ & $0 \mathrm{a}$ & $0.66 \mathrm{~b}-\mathrm{e}$ & $0.22 \mathrm{~A}$ \\
$\mathrm{UV}-\mathrm{C} 1$ & $0 \mathrm{a}$ & $0.34 \mathrm{abc}$ & $2.33 \mathrm{gh}$ & $0.89 \mathrm{DE}$ \\
$\mathrm{UV}-\mathrm{C} 2$ & $0 \mathrm{a}$ & $0.55 \mathrm{bcd}$ & $2.55 \mathrm{~h}$ & $1.03 \mathrm{EF}$ \\
Antimold 60 & $0 \mathrm{a}$ & $0.44 \mathrm{abc}$ & $2.66 \mathrm{~h} \mathrm{i}$ & $1.03 \mathrm{EF}$ \\
Antimold 80 & $0 \mathrm{a}$ & $0.34 \mathrm{abc}$ & $2 \mathrm{fg}$ & $0.78 \mathrm{CDE}$ \\
UV-C 1 + Antimold 60 & $0 \mathrm{a}$ & $0.22 \mathrm{ab}$ & $1 \mathrm{de}$ & $0.41 \mathrm{AB}$ \\
UV-C 1 + Antimold 80 & $0 \mathrm{a}$ & $0.22 \mathrm{ab}$ & $1.77 \mathrm{f}$ & $0.67 \mathrm{BCD}$ \\
UV-C 2 + Antimold 60 & $0 \mathrm{a}$ & $0.32 \mathrm{ab}$ & $1.11 \mathrm{~d}$ & $0.48 \mathrm{ABC}$ \\
UV-C 2 + Antimold 80 & $0 \mathrm{a}$ & $0.22 \mathrm{ab}$ & $1.77 \mathrm{f}$ & $0.67 \mathrm{BCD}$ \\
\hline Zaman ortalamasi & $0 \mathrm{~A}$ & $0.35 \mathrm{~B}$ & $1.90 \mathrm{C}$ & \\
Time average & & &
\end{tabular}




\section{Dış Görünüş}

Sofralık üzümlerin dış görünümü 5 kişiden oluşan bir panelist grup tarafından 1-9 hedonik skalaya göre değerlendirilmiştir. Salkımlarda beklendiği gibi depolama süresi uzadıkça dış görünüş puanları da azalmıştır (Çizelge 8). Daha önceki yapılan çalışmalara benzer şekilde muhafaza süresi sonuna doğru üzüm tanelerinde gerçekleşen matlaşma ve su kaybı ile birlikte salkım görünüm değerlerinde önemli oranda azalmalar görülmüştür (Akbudak ve Karabulut, 2002; Artez-Hernandez ve ark., 2004).

Çizelge 8. 'Red Globe' üzüm çeşidinde derim sonrası farklı uygulamaların depolama süresince dış görünüş üzerine etkisi (1-9 puan)

Table 8. Influence of different postharvest treatments on external appearance during storage period in 'Red Globe' grape cultivar (1-9 point)

\begin{tabular}{|c|c|c|c|c|c|}
\hline & $\begin{array}{l}\text { Derim } \\
\text { Harvest }\end{array}$ & $\begin{array}{l}\text { 1. ay } \\
\text { First } \\
\text { month }\end{array}$ & $\begin{array}{l}\text { 2. ay } \\
\text { Second } \\
\text { month }\end{array}$ & $\begin{array}{l}\text { 3. ay } \\
\text { Third } \\
\text { month }\end{array}$ & $\begin{array}{c}\text { Uygulama } \\
\text { ortalaması } \\
\text { Treatment } \\
\text { average }\end{array}$ \\
\hline Kontrol & $9 a$ & 8.7ab & $6 \mathrm{def}$ & $3.5 \mathrm{j}$ & $6.8 \mathrm{~F}$ \\
\hline $\mathrm{SO}_{2}$ & $9 a$ & 9a & $8.1 b$ & $7 c$ & $8.3 \mathrm{~A}$ \\
\hline UV-C 1 & $9 a$ & 8.7ab & $6.4 c d e$ & 3.9 j & 7DEF \\
\hline UV-C 2 & $9 a$ & $8.5 a b$ & 5.7efg & 4.6hı & 6.9EF \\
\hline Antimold 60 & $9 a$ & $9 a$ & $5.5 f g$ & $3.8 \mathrm{ij}$ & $6.8 \mathrm{~F}$ \\
\hline Antimold 80 & $9 a$ & $9 a$ & 6.1def & $3.4 \mathrm{j}$ & $6.9 \mathrm{EF}$ \\
\hline UV-C $1+$ Antimold 60 & $9 a$ & $9 a$ & $7.1 \mathrm{c}$ & $5.6 \mathrm{fg}$ & $7.6 \mathrm{~B}$ \\
\hline UV-C $1+$ Antimold 80 & $9 a$ & $8.8 \mathrm{ab}$ & $6.4 \mathrm{cde}$ & $5.2 \mathrm{gh}$ & 7.3BCD \\
\hline UV-C $2+$ Antimold 60 & $9 a$ & 8.7ab & $6.9 c$ & $5.2 \mathrm{gh}$ & $7.4 \mathrm{BC}$ \\
\hline UV-C $2+$ Antimold 80 & $9 a$ & $8.6 a b$ & $6.6 \mathrm{~cd}$ & $4.7 \mathrm{~h}$ & 7.2CDE \\
\hline $\begin{array}{l}\text { Zaman ortalaması } \\
\text { Time average }\end{array}$ & $9 A$ & $8.8 \mathrm{~A}$ & $6.5 B$ & $4.7 \mathrm{C}$ & \\
\hline
\end{tabular}

LSD uygulama x zaman: $0.77 \quad$ LSD uygulama: $0.38 \quad$ LSD zaman: 0.24

Uygulamalar içerisinde ise en yüksek ortalama dış görünüş puanı $\mathrm{SO}_{2}$ uygulanmış salkımlarda belirlenmiştir. Muhafaza süresi sonunda $\mathrm{SO}_{2}$ (7 puan), UV-C $1+$ Antimold 60 (5.6 puan), UV-C 1 + Antimold 80 (5.2 puan) ve UV-C 2 + Antimold 60 (5.2 puan) uygulamalarında üzümlerin dış görünüş puanı kabul edilebilir olma sınırı olan 5 puanın üstünde kalmıştır. Diğer uygulamalar ise pazarlanamaz nitelikte bulunmuştur. $\mathrm{SO}_{2}$ uygulanan üzümlerde soğukta muhafaza süresince, çürümelerin ve tane sapı ile salkım iskeleti kararmalarının az olması, görünüm bakımından bu uygulamalara ait üzümlere panelistler tarafından diğer uygulamalara göre daha yüksek ve kabul edilebilir sınırın üzerinde puan verilmesini sağlamıştır. Bu çalışmanın sonuçlarına benzer şekilde Lichter ve ark. (2002) ve Lurie ve ark. (2006)'nın yaptıkları çalışmalarda da $\mathrm{SO}_{2}$ petleri kullanılan üzümlerin daha yüksek beğeniye sahip olduğunu göstermiştir. Kombinasyon uygulamaları içerisinde ise en yüksek puanı UV-C 1 + Antimold 60 uygulaması almıştır. Kontrol, UV-C'nin ve Antimold uygulamalarının tekli uygulamaları 3 aylık depolama sonunda başarılı bulunmamıştır. Bunun sebebi ise bu uygulamalara ait salkımlarda nispeten daha yüksek mantari enfeksiyon ile salkım iskeleti esmerleşmesine bağlanabilir.

\section{Sonuç}

Yapılan bütün fiziksel ve kimyasal analizlerin sonucu genel bir değerlendirme 
yapıldı̆̆ında, $\mathrm{SO}_{2}$ uygulamalarında daha iyi neticeler alınmasına karşın $\mathrm{SO}_{2}$ 'nin insan sağlığına zararlı etkilerinden ve bilindik üzüm tadını etkilemesi sebebiyle alternatif olabilecek uygulamalara yönelim önemli olacaktır. Araştırmada 3 ay süre ile depolama neticesinde $\mathrm{SO}_{2}$ uygulamasına alternatif olabilecek ve en yakın kalite değerlerine sahip olan UV-C 1 + Antimold 60 uygulaması ön plana çıkmıştır. Bundan sonraki çalışmalarda farklı çeşitlerde ve farklı dozda UV-C ışın uygulamaları ve etanol buharı uygulamalarının kombine edildiği çalışmalarla daha etkin ve pratiğe yönelik veriler üretilmeye çalışılabilir.

\section{Teşekkür}

$\mathrm{Bu}$ araştırma "Derim Sonrası UV-C ve Etanol Uygulamalarının Üzüm Meyve Kalitesi İle Muhafaza Süresi Üzerine Etkileri" isimli "NKUBAP.03.GA.16.056" No'lu projeden özetlenmiştir. Projemizi desteklediğinden dolayı Namık Kemal Üniversitesi Rektörlüğü’ne teşekkür ediyoruz.

\section{Kaynaklar}

Ağaoğlu, Y.S., Tuncel, N., Söylemezoğlu, G., 1988. Değişik fümigasyon yöntemlerinin bazı üzüm çeşitlerinin muhafazasına etkileri üzerinde bir araştırma. Türkiye III. Bağcılık Sempozyumu, 31 Mayıs-3 Haziran, 39-45, Bursa.

Akbudak, B., Karabulut, Ö.A., 2002. Üzüm muhafazasında gri küf'den (Botrytis cinerea pers:fr.) kaynaklanan kalite kaybı ve çürümelerin ultraviolet-c (uv-c) ışık uygulamaları ile önlenmesi üzerine bir araştırma. Ulud. Üniv. Zir. Fak. Derg., 16(2): 35-46.

Artes-Hernandez, F., Aguayo, E., Artes, F., 2004. Alternative atmosphere treatments for keeping quality of 'Autumn seedless' table grapes during long-term cold storage. Postharvest Biol. Technol., 31: 59-67.

Bal, E., Kök, D., 2008. Müşküle üzüm çeşidinin soğukta muhafazası üzerine mentol uygulamalarının etkileri. Bahçe Bitkileri Ürünlerinde IV. Muhafaza ve Pazarlama Sempozyumu, 8-11Ekim 2008, 99107, Antalya.

Bal, E., Kök, D., Çelik, S., 2011. Kozak Siyahı üzüm çeşidi üzerine hasat sonrası bazı uygulamaların etkisi. NKÜ Tekirdağ Ziraat Fakültesi Dergisi, 8(2): 6576.

Cemeroğlu, B., 2007. Gıda analizlerinde genel yöntemler. Gıda Analizleri, Cemeroğlu, B. (ed.), s. 45-128, Bizim Büro Basımevi, Ankara.

Chervin, C., El Kereamy, A., Rache, P., Tournaire, A., Roger, B., Westercamp, P., Goubran, F., Salib, S., Kreidl, S., Holmes, R., 2003. Ethanol vapours to complement or replace sulfur dioxide fumigation of table grapes. Acta Hort., 628: 779-784.

Chervin, C., Westercamp, P., Monteils, G., 2005. Ethanol vapours limit botrytis development over the postharvest life of table grapes. Postharvest Biol. Technol., 36: 319-322.

Cia, P., Benato, E.A., Valentini, S.R.T., Anjos, V.D.A., Ponzo, F.S., Sanches, J., Terra, M.M., 2009. Ultraviolet radiation (UV-C) on the postharvest control of Colletotrichum gloeosporioidesin 'Niagara Rosada' grapes. Bragantia, 68: 10091015.

Costa, L., Vicente, A.R., Civello, P.M., Chaves, A.R., Martinez, G.A., 2006. UV-C treatment delays postharvest senescence in broccoli florets. Postharvest Biol. Technol., 39(2): 204-210.

Çandır, E., Özdemir, A.E., Kamiloğlu, Ö., Soylu, E.M., Dilbaz ,R., Üstün, D., 2010. Red Globe üzüm çeşidinin soğukta muhafazasına etanol buharı ve map uygulamalarının etkileri. TOVAG 1070735, $71 \mathrm{~s}$.

Deng, Y., Wu, Y., Li, Y., 2005. Effects of high $\mathrm{O}_{2}$ levels on postharvest quality and shelf life of table grapes during long-term storage. Eur Food Res Technol., 221: 392-397.

Dentener, P.R., Alexander, S.M., Bennett, K.V., McDonald, R.M., 1998. Postharvest control of lightbrown apple moth using ethanol, Acta Hort., 464: 279-284.

Dong, Y.H., Mitra, D., Kootstra, A., Lister, C., Lancaster, J., 1995. Postharvest stimulation of skin color in royal gala apple. J. American Society Hortic. Sci., 120(1): 95-100.

Erbaş, D., Onursal, C.E., Babalık, Z., Koyuncu, M.A., 2014. Üzüm muhafazasında salisilik asit kullanımı. VI. Bahçe Ürünlerinde Muhafaza ve Pazarlama Sempozyumu, 22-25 Eylül 2014, 60-67 Bursa.

Erkan, M., Wang, S.Y., Wang, C.Y., 2008. Effect of UV treatment on antioxidant capacity, antioxidant enzyme activity and decay in strawberry fruit. Postharvest Biol. Technol., 48: 163-171.

Garzon, G.A., Wrolstad, R.E., 2009. Major anthocyanins and antioxidant activity of Nasturtium flowers (Tropaeolum majus).Food Chemistry, 114(1): 4449. 
Kasım, R., Kasım, M.U., 2007. Sebze ve meyvelerde hasat sonrası kayıpların önlenmesinde alternatif bir uygulama: UV-C. Tarım Bilimleri Dergisi, 13(4): 413-419.

Keskin, N., Keskin, S., Çavuşoğlu, Ş., Şevgin, N., Kunter, B., Karadoğan, B., Kalkan, N.N., 2015. Karaerik (Cimin) üzüm çeşidinde hasat sonrası uv-c ve sıcak su uygulamalarının meyve kalitesi ve soğukta muhafaza üzerine etkileri. GAP VII. Tarım Kongresi Bildiri Kitabı, s:34-40.

Koçak, H., Bal, E., 2017. Hasat sonrası UV-C ve yenilebilir yüzey kaplama uygulamalarını kiraz meyve kalitesi ile muhafaza süresi üzerine etkileri. Türkiye Tarımsal Araştırmalar Dergisi, 4(1): 7988.

Kök, D., Bal, E., Bahar, E., 2017. Physical and biochemical traits of selected grape varieties cultivated in Tekirdağ, Turkey. Int. J. Sustainable Agricultural Management and Informatics, 3(3): 215-223.

Lichter, A., Zutkhy, Y., Sonego, O.D., Kaplunov, T., Sarig, P., Ben-Arie, R., 2002. Ethanol controls postharvest decay of table grapes. Postharvest Biol. Technol., 24: 301-308.

Lurie, S., Pesis, E., Gadiyeva, O., Feygenberg, O., BenArie, R., Kaplunov, T., Zutahy, Y., Lichter, A., 2006. Modified ethanol atmosphere to control decay of table grapes during storage. Postharvest Biol. Technol., 42: 222-227.

Marquenie, D., Michiels, C.W., Geeraerd, A.H., Schenk, A., Soontjens, C., Van Impie, J.F., 2002. Using survival analysis to investigate the effect of UV-C and heat treatment on storage rot of strawberry and sweet cherry. International Journal of Food Microbiology, 73: 187-196.

Martinez-Romero, D., Guillen, F., Castillo, S., Valero, D., Serrano, M., 2003. Modified atmosphere packaging maintains quality of table grapes. $J$. Food Sci., 68: 1838-1843.

Nigro, F., Ippolitto, A., Lima, G., 1998. Use of UV-C light to reduce Botrytis storage rot of table grapes. Postharvest Biol. Technol, 13: 171-181.

Özkaya, O., Dündar, Ö., Özdemir, A.E., Dilbaz, R., 2005. Farklı derim sonrası uygulamaların Red Globe üzüm çeşidi muhafazasına etkileri. Alatarım, 4: 44-50.

Rivera, P.D.M., Gardea-Bejar, A.A., Martinez-Tellez, M.A., Rivera, D.M., Gozalez-Aguilar, G.A., 2007. Efectos bioqimicos postcosecha de la irradiacion uvc en frutas y hortalizas. Revista Fitotecnia Mexicana, 30(4): 361-372.

Romero, I., Sanchez-Ballesta, M.T., Maldonado, R., Escribano, M.I., Merodio, C., 2008. Anthocyanin, antioxidant activity and stress-induced gene expression in high $\mathrm{CO}_{2}$-treated table grapes stored at low temperature. Journal of Plant Physiology, 165(5): 522-530.

Sabır, A., Sabır, F.K., Tangolar, S., Bilir, H., Ağar, I.T.,
2006. 'Alphonse Lavallée' üzüm çeşidinin soğukta muhafazası üzerine $\mathrm{SO}_{2}$ jeneratörü ve farklı dozlardaki etanol uygulamalarının karşılaştırılması. Ç.Ü. J. Agric. Fac., 21 (3): 45-50.

Sabır, A., Sabır, F., K., Tangolar, S., Ağar, T., 2008. Etanol ve kükürtdioksit uygulamalarının bazı üzüm çeşitlerinde muhafaza süresi ve kalite üzerine etkileri. Bahçe Ürünlerinde 4. Muhafaza ve Pazarlama Sempozyumu, 8-11Ekim 2008, 441448, Antalya.

Slinkard, K., Singleton, V.L., 1977. Total phenol analysis: automation and comparison with manual methods. American Journal of Enology and Viticulture, 28(1): 49-55.

Söylemezoğlu, G., 2001. Storage of Table Grapes. Ankara Üniversitesi Basımevi, 72s.

Stevens, C., Wilson, C.L., Lu, J.Y., Khan, V.A., Chalutz, E., Droby, S., Kabwe, M.K., Haung, Z., Adeyeye, O., Pusey, L.P., Wisniewski, M.E., West,M., 1996. Plant hormesis induced by ultraviolet light- $C$ for controlling postharvest and diseases of tree fruits. Crop Protection, 15: 129-134.

Şen, F., Kesgin, M., 2014. Effect of different covering materials used during the pre-harvest stage on the quality and storage life of 'Sultana Seedless' grapes. Food Science and Technology, 34(4): 787792.

Torçuk, A.I.., Bal, E., Gülcü, M., Seçkin, U.G., 2016. Etanol buharı uygulamasının kiraz muhafazası üzerine etkilerinin araştırılması. VII. Bahçe Ürünlerinde Muhafaza ve Pazarlama Sempozyumu, 04-07 Ekim 2016, 85-93, Isparta.

Tozlu, C., 2001. Sofralık üzüm çeşitlerinin muhafazası ve pazarlanması aşamalarında kükürt dioksit $\left(\mathrm{SO}_{2}\right)$ kalıntı düzeylerinin belirlenmesi. Yüksek Lisans Tezi, Ankara Üniv. Fen Bilimleri Enst. Bahçe Bitkileri Anabilim Dalı, Ankara. 47s.

Türk, R., Doruk, Y., 1992. Farklı fümigasyon uygulamalarının soğukta muhafaza edilen bazı önemli üzüm çeşitlerinde meyve suyu kükürtdioksit içeriklerine etkisi. Türkiye I. Ulusal Bahçe Bit. Kong., 13-16 Ekim, 511-516, İzmir.

Türkben, C., 2010. Sofralık Üzümlerin Muhafazası. Hasad Yayıncilık, 16-39.

Valizadeh, A., 2015. Farklı derim sonrası uygulamaların sofralık üzümlerin soğukta muhafazasına etkileri. Çukurova Üniversitesi Fen Bilimleri Enstitüsü, Bahçe Bitkileri Anabilim Dalı, Doktora Tezi, 117s.

Vicente, A.R., Pineda, C., Lemoine, L., Civello, P.M., Martinez, G.A., Chaves, A.R., 2005. UV-C treatments reduce decay, retain quality and alleviate chilling injury in pepper. Postharvest Biol. Technol., 35(1): 69-78.

Winkler, A.J., Cook, J.A., Kliewer, W.M., Lider, L.A., 1974. General Viticulture. University of California Press, Berkeley, California. p. 710. 